\title{
Ecological and behavioural risk factors of scrub typhus in central Vietnam: a case-control study
}

\author{
Hanh Thi Duc Tran ${ }^{1,2,3^{*}} \mathbb{0}$, Jan Hattendorf ${ }^{1,3}$, Hung Manh Do ${ }^{4}$, Thanh Tien Hoang ${ }^{4}$, Hang Thi Hai Hoang ${ }^{4}$, \\ Hoa Ngoc Lam ${ }^{5}$, Mai Kim Huynh ${ }^{6}$, Lan Thi Hoang Vu², Jakob Zinsstag ${ }^{1,3}$, Daniel Henry Paris ${ }^{7,8}$ and \\ Esther Schelling 9
}

\begin{abstract}
Background: The risk factors for scrub typhus in Vietnam remain unknown. Scrub typhus caused by Orientia tsutsugamushi often presents as an undifferentiated febrile illness and remains under appreciated due to the limited availability of diagnostic tests. This tropical rickettsial illness is increasingly recognized as an important cause of non-malaria acute undifferentiated fever in Asia. This study aimed to investigate behavioural and ecological related risk factors of scrub typhus to prevent this potentially life-threatening disease in Vietnam.

Methods: We conducted a clinical hospital-based active surveillance study, and a retrospective residence-enrolment date-age-matched case-control study in Khanh Hoa province, Vietnam, from August 2018 to March 2020. Clinical examinations, polymerase chain reaction and enzyme-linked immunosorbent assay lgM tests were applied to define cases and controls. All enrolled participants filled out a questionnaire including demographic socio-economic status, personal behaviors/protective equipment, habitat connections, land use, and possible exposure to the vector. Multivariable conditional logistic regression was used to define the scrub typhus associated risk factors.

Results: We identified 44 confirmed cases and matched them with 152 controls. Among cases and controls, the largest age group was the $41-50$ years old and males accounted for $61.4 \%$ and $42.8 \%$, respectively. There were similarities in demographic characteristics between the two groups, with the exception of occupation. Several factors were significantly associated with acquisition of scrub typhus, including sitting/laying directly on household floor [adjusted $O R(a O R)=4.9,95 \% \mathrm{Cl}: 1.6-15.1, P=0.006]$, household with poor sanitation/conditions ( $\mathrm{aOR}=7.9,95 \% \mathrm{Cl}: 1.9-32.9$, $P=0.005)$, workplace environment with risk (aOR=3.0,95\% Cl: 1.2-7.6, $P=0.020)$, always observing mice around home (aOR=3.7, 95\% Cl: 1.4-9.9, $P=0.008)$, and use of personal protective equipment in the field (aOR=0.4, 95\% Cl: $0.1-1.1, P=0.076)$.

Conclusions: Ecological and household hygiene-related factors were more associated with scrub typhus infection, than individual-level exposure activities in the hyper-endemic area. These findings support local education and allow people to protect themselves from scrub typhus, especially in areas with limitations in diagnostic capacity.
\end{abstract}

Keywords: Ecological, Environmental, Behaviour, Risk factor, Scrub typhus, Orientia tsutsugamushi, Vietnam

*Correspondence: thiduchanh.tran@unibas.ch; hanhtranch@gmail.com ${ }^{1}$ Department of Epidemiology and Public Health, Swiss Tropical and Public Health Institute, Basel, Switzerland

Full list of author information is available at the end of the article

\section{Background}

Scrub typhus is a zoonotic infectious disease caused by Orientia spp. Humans can be exposed to this bacterium through bites of infected larval-stage trombiculid mites, original author(s) and the source, provide a link to the Creative Commons licence, and indicate if changes were made. The images or other third party material in this article are included in the article's Creative Commons licence, unless indicated otherwise in a credit line to the material. If material is not included in the article's Creative Commons licence and your intended use is not permitted by statutory regulation or exceeds the permitted use, you will need to obtain permission directly from the copyright holder. To view a copy of this licence, visit http://creativecommons.org/licenses/by/4.0/. The Creative Commons Public Domain Dedication waiver (http://creativeco mmons.org/publicdomain/zero/1.0/) applies to the data made available in this article, unless otherwise stated in a credit line to the data. 
which are found in rodents of forests and rice fields across the Asia-Pacific region [1-4]. Trombiculid mites have a metamorphosis life-cycle; Female mites lay fertilised eggs in soil, from which 5-7 days later, 6-legged larva (chigger) hatch. These chiggers display host-seeking behaviour by forming clusters on leaves, grasses and twigs above soil surface, and can survive in outdoor environments for weeks-months without a vertebrate host. Chiggers have a large variety of hosts, including maintenance hosts i.e. small mammals (rodents and shrews), ground-dwelling birds, and incidental hosts i.e. larger mammals including humans. Only monkeys, gerbils, hamsters and humans are known to suffer clinically from scrub typhus [1, 5-7]. In severe cases, the disease can progress to multi-organ failure, with pathologic lesions in lungs, kidneys, liver, and brain [8-10]. Absence of eschars, the scrub typhus-specific symptom, makes clinical diagnosis challenging. Currently, standard confirmation tests are for scrub typhus antigen polymerase chain reaction $(\mathrm{PCR})$ and for serologic diagnosis the indirect immunofluorescence assay (IFA) [11]. However, laboratory diagnosis shortly after infection remains difficult, as antibodies do not reach detectable levels for 5-10 days after onset, and the level of Orientia bacteria in the blood for PCR, only reaches detectable levels during acute episodes and is inapparent after appropriate initial antibiotic treatment $[12,13]$. Therefore, scrub typhus is often misdiagnosed, especially in low-middle income countries with limited laboratory capacity [14].

Scrub typhus is a severe public health problem, with one billion people at risk globally, causes an estimated one million cases every year, and has became a leading cause of treatable non-malarial febrile illness [14, 15]. Scrub typhus is a serious public health problem in the Asia-Pacific [16]. In Vietnam, scrub typhus is re-emerging after 40 years of neglect [17]. Only sporadic cases were registered after 1970. However, in 1995, 45 scrub typhus patients were reported in Quang Ninh province, and 449 patients from 2000 to 2002 [18]. Nadjm et al. [19] reported 255 confirmed cases from 24 northern provinces referred to the National Hospital of Tropical Diseases between 2001 and 2003. Khanh Hoa province confirmed 125 scrub typhus cases per year in 2013/2014, resulting in an estimated incidence of 1.1 per 10000 [20]. However, laboratory capacity for scrub typhus diagnosis in Vietnam is not yet designated to cope with increasing numbers. Due to late diagnosis and treatment, Bach Mai national hospital estimated a complication rate of $17 \%$ and a mortality rate of $1.2 \%$ among 251 confirmed patients in 2003 [19, 21].

Epidemiological and ecological information on scrub typhus is very scant in Vietnam. Given the transmission of the bacteria via chiggers, factors at the community level need to be considered to prevent scrub typhus: household sanitation, household/working surroundings, agricultural activities and personal protective measures during outdoor activities [22-24]. As crop fields are an important reservoir for chiggers, farmers are considered a high-risk group for scrub typhus [25]. However, the study in Khanh Hoa in 2013 showed patients with different occupations, including farmers (32\%), students (10\%), private industry workers (7\%), administrative staff (4\%), and $1-5 \%$ other professions: gardeners, traders, housewives, manual laborers, retirees, tour guides and soldiers [26]. These diverse findings suggest that behavioral risk factors associated with living and working environments in endemic areas are more relevant than occupation. Up to date, no further analyses on behavioral factors were performed in Vietnam.

There is an urgent need to gain a better understanding of disease transmission among humans within their ecosystem to make recommendations on practical preventive measures and fostered case-detection-this study aimed to investigate behavioural and ecological related risk factors of scrub typhus.

\section{Methods \\ Study site}

The study took place in Khanh Hoa from August 2018 to March 2020. Khanh Hoa (Latitude $12^{\circ} \mathrm{N}$ and Longitude $109^{\circ} \mathrm{E}$ ) is in coastal South Central of Vietnam. The population was 1.2 million residents (2019) [27], in 9 districts/ townships. The coastal line is $385 \mathrm{~km}$ with many lagoons, bays, and islands. Forests and hilly landscapes cover more than half of province. Khanh Hoa is one of the few provinces with a higher gross product from fishing than from agriculture. The tropical savanna climate allows perennial grasses to grow all year, leads to an open shrub layer [28], suitable environment for chigger abundance and scrub typhus transmission.

There are 12 hospitals in Khanh Hoa: 11 public hospitals [Khanh Hoa Provincial Hospital; Ninh Hoa Hospital (Provincial Hospital Branch), Khanh Hoa Hospital for Tropical Diseases; and 8 district hospitals] and Military Hospital 87. Nha Trang Pasteur Institute (IPN) located in Khanh Hoa is one of two Pasteur Institutes in Vietnam, operating directly under authority of the Vietnamese Ministry of Health. Khanh Hoa is known to be endemic for scrub typhus for over 50 years. Scrub typhus was reported among United States Air Force personnel in Khanh Hoa in 1969 [29]. In 2013-2014, 125 confirmed cases per year occurred in 8 of the 9 districts [20].

\section{Study design}

We investigated scrub typhus risk factors using a hospital-based clinical active surveillance, and a retrospective 
residence-enrolment date-age-matched case-control study to determine risk factors and protective measures associated to disease.

\section{Hospital-based clinical surveillance}

Active surveillance was done at the Military Hospital 87, and 10 of 11 public hospitals of Khanh Hoa, excluding Truong Sa Island district hospital due to accessibility.

All clinical diagnoses during hospitalization admission were made by trained local physicians following suspected acute scrub typhus case definition (Additional file 1: Table S1). All patients satisfying criteria were asked for their informed consent to be enrolled. Demographic and clinical data was collected with standardized questionnaires by trained health staffs. Blood specimens were collected from all enrolled patients at admission and discharge [each 2 tubes, with and without ethylenediaminetetraacetic acid (EDTA)]. Using EDTA blood samples, buffy coat and plasma centrifugation $(616 \times g$ during $15 \mathrm{~min}$ ) was conducted within $24 \mathrm{~h}$ by trained technicians and stored at $2-8{ }^{\circ} \mathrm{C}$ in the hospital laboratory of [30], before transfer to IPN, for PCR and enzyme-linked immunosorbent assay (ELISA) [30]. All samples were labeled with the subject's unique identification number (ID) and preserved in $-20{ }^{\circ} \mathrm{C}$ freezer at the Department of Microbiology and Immunology until further processing.

\section{Case-control study and sample size}

For each confirmed acute scrub typhus case (Additional file 1: Table S1), residence-enrolment date-age-matched controls were enrolled upon their informed consent.

Using Stata software version 14.0 (StataCorp, Texas, USA), we initially calculated a sample size of 128 cases and 512 controls for a matched case-control study, to detect a true odds ratio of 0.5 with $90 \%$ power at the $5 \%$-significance level. Taking a ratio of cases and controls of 1:4, a prevalence of exposure (wearing a long-sleeved shirt/trousers for outdoor activities) of $66 \%$ among controls and a correlation of exposure between cases and control (rho) of 0.2 were assumed. Facing difficulties with enrolment of cases and controls due to COVID-19 pandemic, we adjusted our calculation and aimed for a more common $80 \%$ power. We calculated that 50 cases and 200 controls would be sufficient to detect an odds ratio of 0.4 with $80 \%$ power using the same set of assumptions.

For each confirmed case, we enrolled four matched controls: two hospital and two community controls. The inclusion and exclusion criteria of cases and controls were according to the Vietnam national guideline on diagnosis and treatment of infectious diseases 2016 [31] (Additional file 1: Table S1).
Hospital and community controls were defined as residents with no acute scrub typhus, without fever or with fever $\geq 4$ days. The 4 day criteria accounted for sufficient time to develop a detectable immunoglobulin M (IgM) titer increase [32]. Based on evidence of macro-level factor effects on scrub typhus exposure risk, i.e. provincial climate (dry/rainy seasons), the controls were enrolled no longer than one month since the date of the case confirmation.

To prevent overmatching, hospital controls were selected in the same district as the case, however from any other commune than the case's commune. Regarding community controls, for each confirmed case, a list of community controls was prepared by the commune health center, including all eligible persons living around the case household within $500 \mathrm{~m}$, but not next door [7]. Two persons randomly chosen from the list were invited to participate and asked for their informed consent. At time of enrolment, blood samples were taken with the same sampling/storage procedure as described for suspected cases.

Using a residence-enrolment date-age-matched casecontrol study to determine disease risk factors allowed to minimise effects of ecological confounders related to residence such as mice density, changes of humidity, rain, temperature affecting chigger abundance, its chance to stick on people, and therefore changing exposure probability of people. Enrolment within one month limited changes in households' $(\mathrm{HH})$ context and conditions. Age-matched case-control design helped to control potential confounders related to age such as typical work activities, occupations, behavior routines among each age group. While persons in the same communes (casecommunity controls) were likely to share some same working behaviours and personal protective equipment (PPE) wearing routines, the case-control design for both hospital and community controls was thought to address disadvantages of case-community controls while testing risk factors based on varied behaviours and household contexts across different areas.

\section{Laboratory diagnostic assays}

Buffy coat and plasma specimens from cases and controls were tested at IPN, using semi-nested PCR for Orientia spp. and using IgM enzyme linked immunosorbent assay (ELISA), (Scrub Typhus Detect ${ }^{\mathrm{TM}}$ IgM ELISA, InBios International Inc., Seattle, WA, USA) for detection of antibodies to $O$. tsutsugamushi antigens.

\section{PCR assay}

A novel in-house semi-nested PCR on buffy coat, developed by IPN, was used for detection of partial $56-\mathrm{kDa}$ outer membrane protein gene of O. tsutsugamushi [30]. 
Primers included 2 forward primers with the sequence of (F1): CAATGTCTGCRTTGTCRTTG; (F2): CCKTTTTCIGCTRGTGCGATAG and one reverse primer with sequence of (R): ATAGYAGGYTGAGGHGGYGTA AG. PCR was done with specimens of 114 suspected cases with peripheral blood mononuclear cells (PBMCs) samples (10 suspected cases without PBMCs).

\section{ELISA assays}

The Scrub Typhus Detect IgM ELISA (part no. 500242, Lot no. XM5033; InBios International Inc., Seattle, WA, USA) was used for 395 serum samples of 114 suspected cases (95 paired sera hospital admission and discharge, and 19 single admission sera), 103 hospital controls, and 83 community controls. The ELISA used recombinant p56kD type specific antigens of O. tsutsugamushi Karp, Kato, Gilliam, and TA716 strains to detect scrub typhus IgM antibodies. The manufacturer's manual was followed exactly. All sera were tested at a 1:100 dilution and the absorbance measured at $450 \mathrm{~nm}$ using a microplate reader to give a final optical density (OD $450 \mathrm{~nm}$ ) result. The test kit was validated for diagnosis of acute scrub typhus in Asian countries [33, 34]. The OD positivity cut-off titer of 0.8 was used-this had previously shown a sensitivity of $91.5 \%$, specificity of $88.3 \%$ for admission samples, and sensitivity of $69.8 \%$ and specificity of $89.5 \%$ for convalescent samples in another study under comparable conditions [34].

\section{Building the questionnaire}

The individual questionnaire was built on framework of landscape determinants of disease transmission [35]. The same questionnaire was applied to cases and controls. Participants were asked about 5 main items composed of several specific topical questions: (i) socio-economic status, (ii) behaviors related to land/sand/soil/grass/bushes and their PPE, (iii) species' habitat connections, (vi) land use, and (v) vector contact (Additional file 4: Figure S1).

To develop knowledge around the 5 topics, 12 in-depth interviews with two local scrub typhus epidemiologists, four heads of community health centers (where scrub typhus cases occurred the past years) and six residents (farmers, forest workers, governmental officers) explored local cultivation routines, farming seasons, PPE for daily working use, outdoor activities, and local languages. Following this contextualized "daily-life" assessment, a structured questionnaire and an environment observation checklist were constructed.

\section{Pre-testing and revision of the questionnaire}

The questionnaire was pretested with 30 residents including former scrub typhus patients. The questionnaire was revised according to (i) specificity of questions, (ii) understandability and clearness, (iii) order (reflecting a daily life cycle), (iv) suitability with local context, (v) jumping questions, (vi) language, and (vii) duration of interview. Few cross-check questions were designed information quality checks. Data from pre-testing was not included in our study. The final questionnaire included a total of 96 questions and took about $40 \mathrm{~min}$ to complete (30 min for questions and $10 \mathrm{~min}$ for the environment observation checklist).

\section{Data collection}

Interviews with cases were conducted within 30 days after laboratory confirmation. In parallel, controls were enrolled, tested and interviewed. Data collectors worked at the Department of Epidemiology, IPN, and the team of four all had experiences from the study in 2014 [36]. A trained laboratory technician joined the field data collection team. Every day, the data supervisor checked total numbers and content of all (paper-based) forms collected. Incomplete forms were completed by the data collector or after re-contacting the participants. This was the case in a total of $10 \%$ of questionnaires.

Coordinates of all participants' households were collected using a short form built in Open Data Kit (ODK) on Android devices (Samsung table) [37], before uploading at http://sg.smap.com.au/. GPS accuracy was set up $\pm 5 \mathrm{~m}$.

\section{Data management and quality}

The unique ID included a group ID. The composite code was cross checked. The completed questionnaires were double entered by 2 independent data entry clerks, using Epi data 3.1 (EpiData Association, Odense M, Denmark). After that the data was compared using Epi data 3.1 Mismatches were corrected case by case using Stata 15.0 (StataCorp, Texas, USA) to have a clean dataset.

\section{Statistical analyses Generating new variables}

Five PPEs for field work (socks, boots, long/extra shirt, long/extra trousers, and gloves) were in 2 questions: one binary, and one on the frequency of use on a range from 1 to 10 that was further categorized to the binary variable "use of PPE in the field". "Use of PPE in the field" meant that the person used all 5 PPEs with a minimum frequency of 5/10 times when working in the field.

We used a pre-specified meaningful grouping algorithm to combine related exposure variables into a single binary or ordinal composite variable: (a) "field work group", (b) "work around house group", (c) "household $(\mathrm{HH})$ with poor sanitation/conditions", (d) " $\mathrm{HH}$ surroundings with risk" and (e) "workplace environment with risk". The key risk habitats for the presence 
of infected chiggers in Southeast Asia were (i) forests, bushes, shifting cultivation area, and (ii) water meadows including grassy edges of water bodies and seepages in drier areas [7, 38-42]. All participants/HH/workplace environment characteristics that related to at least to one of these key risk habitats and were defined as the highest risk group. The others were defined as lower risk groups.

In detail, "field work group" was generated as an ordinal composite variable with 5 sub-groups from highest to lowest risk, including: (i) work in forest/hilly field and others, (ii) work in vegetable garden and others (except forest/hilly areas), (iii) work in sugar cane/crop/rice field and others (except forest/hilly areas/vegetable garden), (iv) work in fruit/industrial tree gardens and others (except forest/hilly areas/vegetable garden/sugarcane/ crop/rice field), and (v) no work related to land/sand. By the same way, "work around house group" was created as an ordinal composite variable with 5 sub-groups, containing: (i) watering plants/bonsai or carpenting and others, (ii) cleaning around house and others (except watering plants/bonsai or carpenting), (iii) clearing bushes/barns and others (except watering plants/bonsai, carpenting, cleaning around house), and (iv) no activities around house. "HH with poor sanitation/conditions", the binary composite variable, was generated as $\mathrm{HH}$ with at least one of following characteristics: bushes within $5 \mathrm{~m}$, a mud yard, a mud house floor, or drainage on yard. Two other binary composite variables, "HH surroundings with risk" and "workplace environment with risk" were defined as $\mathrm{HH}$ or workplace surrounded by at least one of four natural characteristics: in/close to forest, in/close to hilly field, near water bodies within $100 \mathrm{~m}$ or bushes within $10 \mathrm{~m}$.

These composite variables were very useful in examining effect of the full set of related exposure variables, while people or $\mathrm{HH}$ could have one or many related exposures of scrub typhus.

\section{Statistical analyses}

We have used composite (as described above) and single variables from the questionnaire. Descriptive statistics included variables to explore major differences between groups. Comparisons of demographic, social, and potential risk factor variables between cases and all controls were analysed using univariable conditional logistic regression. Strength of associated exposures for scrub typhus cases as opposed to controls was expressed by the matched odds ratio. In primary analyses, we pooled both control groups to ensure sufficient statistical power. We used conditional logistic regression to estimate odds ratios and corresponding 95\% confidence intervals. In subsequent analyses, we analysed two control groups separately. Community controls were analysed with conditional logistic regression. For hospital controls we preferred adjusted logistic regression as recommended [43]. All analyses were conducted using Stata 15.0 (StataCorp, Texas, USA).

In initial analyses, all potential risk factors were selected by biological plausibility, professional knowledge via literature review, and prior analyses adjusted for field study experience before consideration in models. Subsequently, all potential explanatory variables with $P<0.1$ in matching univariable models were retained and considered in multivariable models using pooled sample data. The multivariable model was derived using manual backward selection, and considered for effects of retained explanatory variables, confounders and interaction terms. Comparing Akaike information criterion (AIC) of the models, we decided which model had the best fit to our data. In addition, we had the other two models, one comparing cases and hospital controls (subsample 1 ) and one for cases and community controls (subsample 2). Using the selected potential risk factor variables, the same data analyses procedure described above was applied to two subsamples. We present here results of the final model.

To build distribution maps, satellite imagery of Khanh Hoa captured from Google Earth was used to create a base-map. GIS software ArcGIS 10.6.1 (Esri, California, USA) was used for mapping.

\section{Results}

The study flow chart is shown in Fig. 1. A total of 114 suspected acute scrub typhus cases were initially enrolled to the study. Paired blood specimens (admission and discharge) were collected from 95 suspected cases and admission samples alone from 19 ones. Buffy coats were collected from 104 suspects. Forty-five of the 114 suspects were positive with PCR buffy coat and/or ELISA IgM. After exclusion of one positive due to living outside the study area, we included 44 confirmed cases in the case-control study. Eighty-three hospital controls were initially aligned to the matching-criteria to the 44 confirmed cases, however, 13 of these were excluded for other criteria. Finally, 70 hospital controls were included. We enrolled 82 eligible community controls. In summary, we included data of 196 participants, whereof, 44 confirmed scrub typhus cases and 152 controls.

Socio-demographic findings and geographic distributions Among cases and controls $61.4 \%$ and $42.8 \%$ were males, respectively. The largest age group was $41-50$ years old, and comparable between the case and control groups. The two groups were balanced with respect to ethnicity, education level, family size, excepting occupations (9.1\% farmers among cases and $21.1 \%$ among controls) 


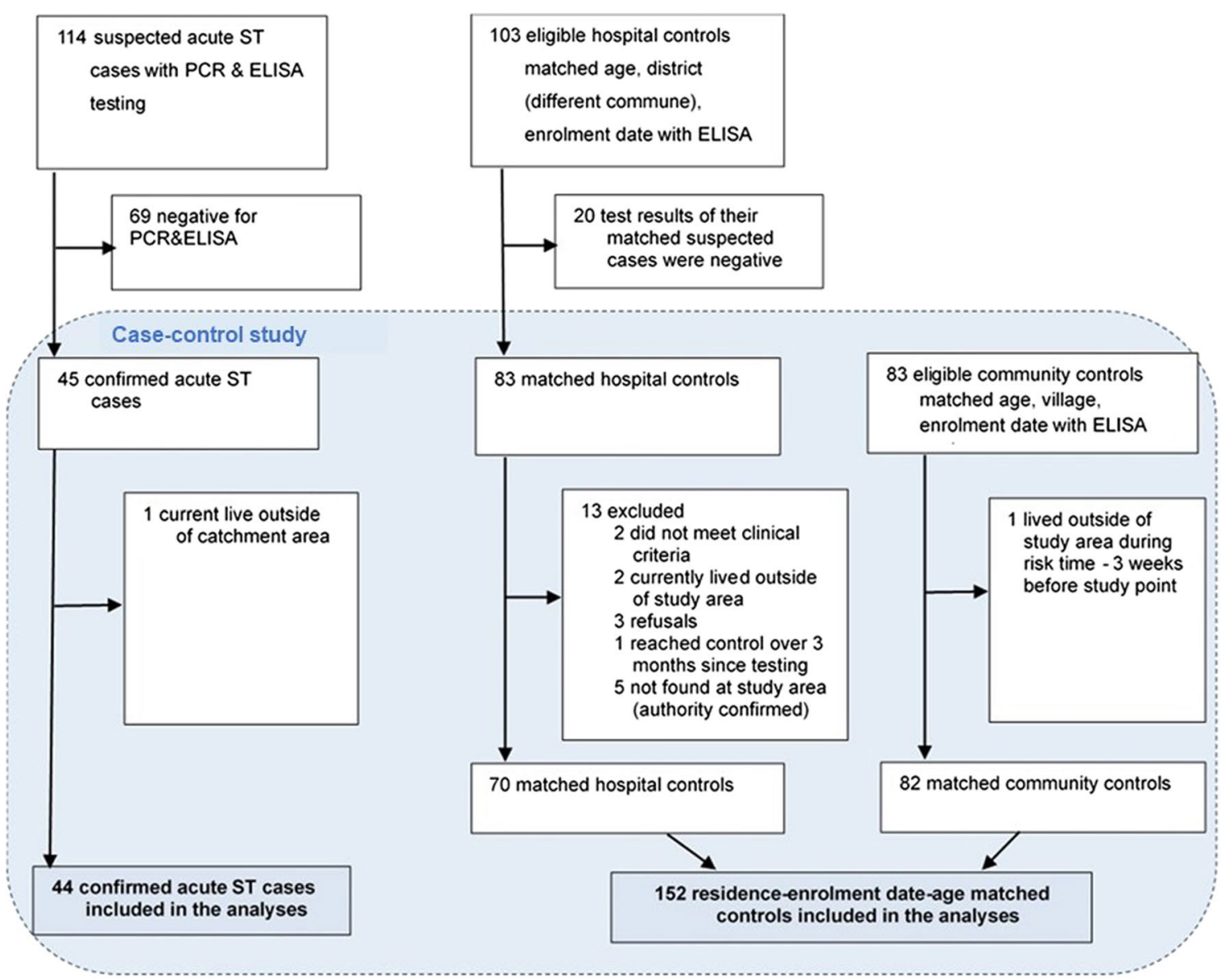

Fig. 1 Study flow chart: overview of enrolment of scrub typhus cases, hospital and community controls. ST: scrub typhus; PCR: Polymerase chain reaction; ELISA: Enzyme-linked immunosorbent assay

and working in forests/mountain fields (27.3\% among cases and $11.2 \%$ among controls). The majority of cases and controls had no history of scrub typhus $(90.9 \%$ and $98.7 \%$, respectively) (Table 1 ).

We plotted geographic distributions of scrub typhus confirmed cases (A) and controls (B) (Fig. 2). Scrub typhus cases occurred in all 8 districts. There were differences in numbers of confirmed cases across the districts. Most cases occurred in Ninh Hoa while a few were in other districts. Cases were observed in all zones, including flat areas, near mountains, near forests, or alongside beaches.

\section{Risk factors}

Exposures associated with scrub typhus in univariable conditional logistic regression are provided in Table 2 . Cases were more likely than controls to get scrub typhus when they worked in forest/hilly areas [matched odds ratio $(\mathrm{mOR})=23.9,95 \% \mathrm{CI}: 5.8-98.2]$, worked in fruit/ industrial tree gardens $(\mathrm{mOR}=10.5,95 \% \mathrm{CI}: 1.6-69.4)$, urinated in the forest/near bushes/field $(\mathrm{mOR}=5.6$, 95\% CI: 2.4-13.1), passed regularly at the river side $(\mathrm{mOR}=2.8,95 \% \mathrm{CI}: 1.4-5.6)$, used the same work clothes the next day $(\mathrm{mOR}=2.4,95 \% \mathrm{CI}: 1.0-5.6)$, sat/laid directly on the HH floor ( $\mathrm{mOR}=3.9,95 \% \mathrm{CI}: 1.7-8.7)$.

Always observing mice around home $(\mathrm{mOR}=3.1,95 \%$ CI: 1.5-6.6), $\mathrm{HH}$ surroundings with risk $(\mathrm{mOR}=8.4$; 95\% CI: 2.4-29.1), and workplace environment with risk ( $\mathrm{mOR}=3.6,95 \% \mathrm{CI}: 1.7-7.7)$ were associated with increased acquisition risk. Lower risks for acquiring scrub typhus were the use of PPE in the field and changing clothes when at home $(\mathrm{mOR}=0.3,95 \% \mathrm{CI}: 0.2-0.7$; and $\mathrm{mOR}=0.3,95 \% \mathrm{CI}: 0.1-0.8$, respectively).

The most relevant factors associated with scrub typhus in the multivariable conditional logistic regression model are presented in Table 3. We found four significant risk factors and one protective determinant for scrub typhus, including: sitting/laying directly on $\mathrm{HH}$ floor [adjusted odds ratio $(\mathrm{aOR})=4.9,95 \%$ CI: $1.6-15.1], \mathrm{HH}$ with poor sanitation/conditions $(\mathrm{aOR}=7.9,95 \%$ CI: 1.9-32.9), 
Table 1 Socio-demographic comparison between scrub typhus cases and controls, Khanh Hoa, August 2018-March 2020

\begin{tabular}{|c|c|c|c|c|}
\hline Variables & Cases $(n=44) n(\%)$ & $\begin{array}{l}\text { Controls }(n=152) n \\
(\%)\end{array}$ & $P$-value & $\mathrm{mOR}(95 \% C l)^{\mathrm{a}}$ \\
\hline \multicolumn{5}{|l|}{ Age group, years } \\
\hline$\leq 30$ & $12(27.3 \%)$ & $45(29.6 \%)$ & - & - \\
\hline $31-40$ & $11(25.0 \%)$ & $27(17.8 \%)$ & 0.29 & $1.9(0.6-6.4)$ \\
\hline $41-50$ & $13(29.6 \%)$ & 47 (30.9\%) & 0.78 & $1.2(0.3-5.3)$ \\
\hline$\geq 51$ & $8(18.2 \%)$ & $33(21.7 \%)$ & 0.98 & $1.0(0.2-6.5)$ \\
\hline \multicolumn{5}{|l|}{ Sex } \\
\hline Male & $27(61.4 \%)$ & $65(42.8 \%)$ & 0.05 & $2.0(1.0-4.1)$ \\
\hline Female & $17(38.6 \%)$ & $87(57.2 \%)$ & - & - \\
\hline \multicolumn{5}{|l|}{ Ethical group } \\
\hline Kinh & 38 (86.4\%) & $125(82.8 \%)$ & 0.35 & $1.8(0.6-5.9)$ \\
\hline Others & $6(13.6 \%)$ & $26(17.2 \%)$ & - & - \\
\hline \multicolumn{5}{|l|}{ Education } \\
\hline Illiteracy & $2(4.7 \%)$ & $10(6.6 \%)$ & - & - \\
\hline Primary school & $16(37.2 \%)$ & 35 (23.0\%) & 0.34 & $2.3(0.4-12.4)$ \\
\hline Secondary school & $11(25.6 \%)$ & 60 (39.5\%) & 0.87 & $0.9(0.2-4.7)$ \\
\hline High school & $11(25.6 \%)$ & $30(19.7 \%)$ & 0.56 & $1.6(0.3-8.7)$ \\
\hline University and higher & $3(7.0 \%)$ & $17(11.2 \%)$ & 0.69 & $0.7(0.1-5.0)$ \\
\hline \multicolumn{5}{|l|}{ Occupation } \\
\hline Not related field/sea/sand & $16(36.4 \%)$ & $78(51.3 \%)$ & - & - \\
\hline Farmer & $4(9.1 \%)$ & $32(21.1 \%)$ & 0.17 & $0.6(0.4-2.1)$ \\
\hline Gardening, growing vegetables & $4(9.1 \%)$ & $6(4.0 \%)$ & 0.11 & $3.5(0.8-16.0)$ \\
\hline Working in forests/ mountain fields & $12(27.3 \%)$ & $17(11.2 \%)$ & 0.006 & $4.5(1.5-12.9)$ \\
\hline Others & $8(18.8 \%)$ & $19(12.5 \%)$ & 0.24 & $1.9(0.7-5.4)$ \\
\hline \multicolumn{5}{|c|}{ Number of people living in same household } \\
\hline 1-3 people/household & $9(20.5 \%)$ & $40(26.5 \%)$ & - & - \\
\hline 4-5 people/household & $22(50.0 \%)$ & $75(49.7 \%)$ & 0.43 & $1.4(0.6-3.5)$ \\
\hline$\geq 6$ people/household & $13(29.6 \%)$ & $36(23.8 \%)$ & 0.30 & $1.7(0.6-4.8)$ \\
\hline \multicolumn{5}{|l|}{ History of scrub typhus } \\
\hline \multicolumn{5}{|l|}{ Participants 2 years prior to study } \\
\hline Yes & $4(9.1 \%)$ & $2(1.3 \%)$ & 0.02 & $7.3(1.3-39.9)$ \\
\hline No & $40(90.9 \%)$ & $150(98.7 \%)$ & - & - \\
\hline \multicolumn{5}{|l|}{ Family members 2 years prior to study } \\
\hline Yes & $2(4.7 \%)$ & $5(3.3 \%)$ & 0.64 & $1.5(0.3-8.5)$ \\
\hline No & $41(95.4 \%)$ & $147(96.7 \%)$ & - & - \\
\hline \multicolumn{5}{|l|}{ Number of years living in same house } \\
\hline$\leq 1$ year & $2(4.6 \%)$ & $2(1.3 \%)$ & - & - \\
\hline $2-3$ years & $2(4.6 \%)$ & $6(4.0 \%)$ & 0.48 & $0.4(0.04-4.6)$ \\
\hline$\geq 4$ years & 40 (90.9\%) & $144(94.7 \%)$ & 0.22 & $0.3(0.04-2.1)$ \\
\hline
\end{tabular}

a mOR: matched odds ratio, using conditional logistic regression **bold: $P$-value $<0.05$

workplace environment with risk $(\mathrm{aOR}=3.0,95 \% \mathrm{CI}$ : 1.2-7.6), always observing mice around home $(\mathrm{aOR}=3.7$, 95\% CI: 1.4-9.9) and, as protective factor with low statistical evidence, use of PPE in the field $(\mathrm{aOR}=0.4,95 \% \mathrm{CI}$ : $0.1-1.1$ ).

Risk factors among cases-hospital controls (i.e. living in different communes) were not similar to those among cases-community controls (i.e. living in same commune).
Among people living in different communes, always observing mice around home, workplace environment with risk were associated with increased scrub typhus risk $(\mathrm{aOR}=5.4,95 \% \mathrm{CI}: 1.7-17.1$; and $\mathrm{aOR}=4.9,95 \% \mathrm{CI}$ : 1.6-15.3, respectively). Changing clothes when at home was likely to protect from scrub typhus $(\mathrm{a} O R=0.1,95 \%$ CI: 0.02-0.6). Among persons in same commune, sitting/laying directly on $\mathrm{HH}$ floor and adult men were risk 


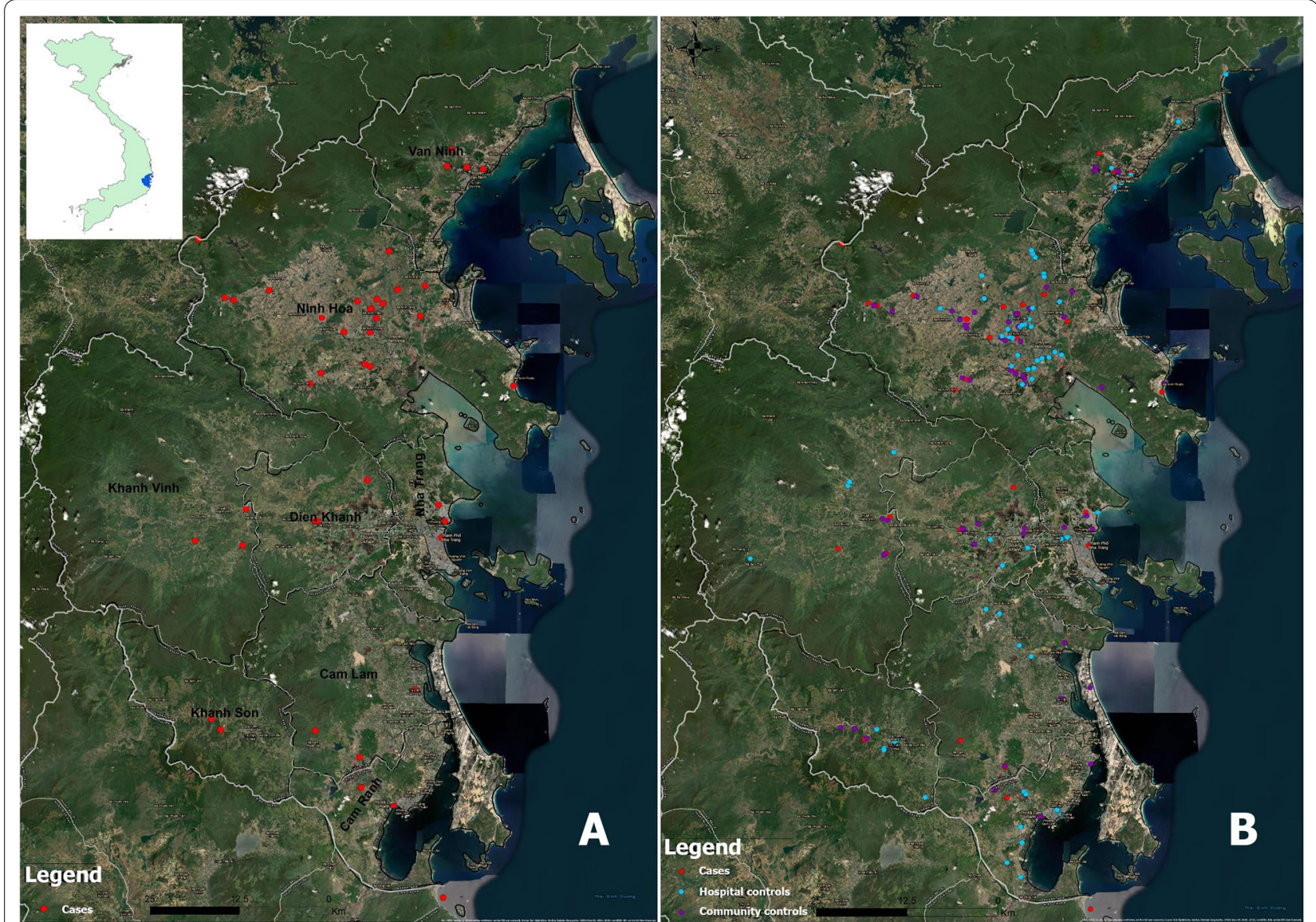

Fig. 2 Geographic distributions of scrub typhus cases and controls, Khanh Hoa, August 2018-March 2020

factors of scrub typhus $(\mathrm{aOR}=35.3,95 \% \mathrm{CI}$ : 3.4-368.8; and $\mathrm{aOR}=6.3,95 \% \mathrm{CI}: 1.1-34.4$, respectively). Use of PPE in the field was a potential factor to protect from bites of mites in same endemic communes $(\mathrm{aOR}=0.21$, 95\% CI: 0.04-1.09) (Additional files 2, 3: Tables S2 and S3).

\section{Discussion}

Scrub typhus is acquired through the bite of infected chiggers. Based on biological plausibility pathways, we present the discussion in order from proximal (direct chigger exposure) to distal risk factors (always observing mice around home). The five main factors for scrub typhus acquisition in this study were (i) sitting/laying directly on $\mathrm{HH}$ floor, (ii) use of PPE in the field, (iii) $\mathrm{HH}$ with poor sanitation/conditions, (iv) workplace environment with risk, and (v) always observing mice around home.

\section{Sitting/laying directly on $\mathrm{HH}$ floor}

Sitting/laying directly on $\mathrm{HH}$ floor was the most direct exposure to acquire scrub typhus in our endemic area
$(\mathrm{aOR}=4.9,95 \% \mathrm{CI}: 1.6-15.1)$. One likely explanation is that people were bitten by infected chiggers when sitting/laying directly on $\mathrm{HH}$ floor. Chiggers of mites of Leptotrombidium deliense and Ascoschoengastia (Laurentella) indica (species of Trombiculidae mite family) were key chigger species transmitting Orientia spp. in Southeast Asia, and found on indoor and outdoor mice [1-3]. In Khanh Hoa, $L$. deliense and $A$. indica were found on house mice, accounting for $11.9 \%$ of all detected transmission mites [53]. Among house rodents, the proportion of mite infestation was $82.7 \%$ for Rattus norvegicus, followed by $R$. flavipestus (66,7\%), and R. exulans (34,1\%). Proportions of $R$. norvegicus and R. flavipestus with Orientia spp. positivity were $1.7 \%$ and $0.24 \%$, respectively (Khanh Hoa, 2013-2014) [44]. One scrub typhus paediatric patient (10 months) in Khanh Hoa was confirmed by IPN in 2013 [45]. Evidence suggests that sitting/laying directly on $\mathrm{HH}$ floor, is strongly associated with an increased risk of acquiring scrub typhus. 
Table 2 Exposures associated with scrub typhus in Khanh Hoa, Vietnam, August 2018-March 2020

\begin{tabular}{|c|c|c|c|c|}
\hline Variables & Cases $(n=44) n(\%)$ & Controls $(n=152) n(\%)$ & $P$-value & $\operatorname{mOR}(95 \% C l)^{\mathrm{a}}$ \\
\hline \multicolumn{5}{|l|}{ Field work group } \\
\hline Work in forest/ hilly field and others & $26(59.1 \%)$ & $24(15.8 \%)$ & $<0.001$ & $23.9(5.8-98.2)$ \\
\hline Work in vegetable garden and others & $6(13.6 \%)$ & $15(9.9 \%)$ & 0.07 & $3.9(0.9-16.6)$ \\
\hline Work in sugarcane/crop/rice field and others & $3(6.8 \%)$ & $37(24.3 \%)$ & 0.88 & $0.9(0.1-5.2)$ \\
\hline Work in fruit/industrial tree garden and others & $3(6.8 \%)$ & $8(5.3 \%)$ & 0.02 & $10.5(1.6-69.4)$ \\
\hline No work related to land/sand & $6(13.6 \%)$ & $68(44.7 \%)$ & - & - \\
\hline \multicolumn{5}{|l|}{ Use of personal protective equipment in the field } \\
\hline Yes & $14(31.8 \%)$ & $86(56.6 \%)$ & 0.004 & $0.3(0.1-0.7)$ \\
\hline No & $30(68.2 \%)$ & $66(43.4 \%)$ & - & - \\
\hline \multicolumn{5}{|l|}{ Urinating in the forest/near bushes/field } \\
\hline Yes & $25(56.8 \%)$ & $34(22.4 \%)$ & $<0.001$ & $5.6(2.4-13.1)$ \\
\hline No & $19(43.2 \%)$ & $118(77.6 \%)$ & - & - \\
\hline \multicolumn{5}{|l|}{ Using the same work clothes the next day } \\
\hline Yes & $15(34.1 \%)$ & $30(19.7 \%)$ & 0.05 & $2.4(1.0-5.6)$ \\
\hline No & $29(65.9 \%)$ & $122(80.3 \%)$ & - & - \\
\hline \multicolumn{5}{|l|}{ Changing clothes when at home } \\
\hline Yes & $34(77.3 \%)$ & 140 (92.1\%) & 0.01 & $0.3(0.1-0.8)$ \\
\hline No & $10(22.7 \%)$ & $12(2.9 \%)$ & - & - \\
\hline \multicolumn{5}{|l|}{ Always observing mice around home } \\
\hline Yes & $21(47.73 \%)$ & $37(24.34 \%)$ & 0.003 & $3.1(1.5-6.6)$ \\
\hline No & $23(52.27 \%)$ & $115(75.66 \%)$ & . & . \\
\hline \multicolumn{5}{|l|}{ Work around house group } \\
\hline Watering plants/bonsai or carpenting + others & $19(43.2 \%)$ & $54(35.5 \%)$ & 0.48 & $1.3(0.6-2.9)$ \\
\hline Cleaning around the house + others & $6(13.6 \%)$ & $34(22.4 \%)$ & 0.46 & $0.7(0.2-1.9)$ \\
\hline Clearing bushes/barns + others & $4(9.1 \%)$ & $9(5.9 \%)$ & 0.36 & $1.9(0.4-7.2)$ \\
\hline No activities around house & $15(34.1 \%)$ & $55(36.2 \%)$ & - & - \\
\hline \multicolumn{5}{|l|}{ Passing regularly at the riverside } \\
\hline Yes & $23(52.3 \%)$ & $42(27.6 \%)$ & 0.004 & $2.8(1.3-5.6)$ \\
\hline No & $21(47.7 \%)$ & $110(72.4)$ & & \\
\hline \multicolumn{5}{|l|}{ Sitting/laying directly on household floor } \\
\hline Yes & $23(52.3 \%)$ & $40(26.7 \%)$ & 0.001 & $3.9(1.7-8.7)$ \\
\hline No & $21(47.7 \%)$ & $110(73.3 \%)$ & & \\
\hline \multicolumn{5}{|l|}{ Household with poor sanitation/conditions } \\
\hline Yes & $41(93.2 \%)$ & $96(63.2 \%)$ & $<0.001$ & $8.4(2.4-29.1)$ \\
\hline No & $3(6.8 \%)$ & $56(36.8 \%)$ & & \\
\hline \multicolumn{5}{|l|}{ Household surroundings with risk } \\
\hline Yes & $22(50 \%)$ & $45(29.6 \%)$ & 0.007 & $3.1(1.4-7.2)$ \\
\hline No & $22(50 \%)$ & $107(70.4 \%)$ & & \\
\hline \multicolumn{5}{|l|}{ Workplace environment with risk } \\
\hline Yes & $30(68.18 \%)$ & $58(38.16 \%)$ & 0.001 & $3.6(1.7-7.7)$ \\
\hline No & $14(31.82 \%)$ & $94(61.84 \%)$ & . & . \\
\hline
\end{tabular}

${ }^{a} \mathrm{mOR}$, matched odds ratio, using univariable conditional logistic regression, ${ }^{* *}$ bold: $P$-value $<0.05$

\section{Use of PPE in the field}

Benefits of PPE usage in preventing scrub typhus were reported. Most authors considered a benefit of wearing gumboots, aprons, long-sleeved shirt, long-sleeved clothes as separate items [45-48]. In this study, we did not observe benefits of single measures-our findings rather suggest that an advantage lies in using the full PPE, including all 5 items: socks, boots, long/ extra shirt, long/extra trousers, and gloves, potential to protect persons from bites of mites in the endemic area $(\mathrm{aOR}=0.4,95 \% \mathrm{CI}: 0.1-1.1)$. This highlights that 
Table 3 Risk factors of scrub typhus resulting from the conditional multivariable logistic regression

\begin{tabular}{|c|c|c|c|c|c|}
\hline Risk factors & $\begin{array}{l}\text { Cases }(n=44) \\
n(\%)\end{array}$ & $\begin{array}{l}\text { Controls }(n=152) \\
n(\%)\end{array}$ & $\mathrm{mOR}(95 \% C l)^{\mathrm{a}}$ & $\mathrm{aOR}(95 \% C l)^{\mathrm{b}}$ & $P$-value \\
\hline Sitting/laying directly on household floor & $23(52.3 \%)$ & $40(26.7 \%)$ & $3.9(1.7-8.7) 0.328779$ & $4.9(1.6-15.1)$ & 0.006 \\
\hline Use of personal protective equipment in the field & $14(31.8 \%)$ & $86(56.6 \%)$ & $0.3(0.2-0.7)$ & $0.4(0.1-1.1)$ & 0.076 \\
\hline Household with poor sanitation/conditions & $41(93.2 \%)$ & $96(63.2 \%)$ & $8.4(2.4-29.1)$ & $7.9(1.9-32.9)$ & 0.005 \\
\hline Workplace environment with risk & $30(68.18 \%)$ & $58(38.16 \%)$ & $3.6(1.7-7.7)$ & $3.0(1.2-7.6)$ & 0.020 \\
\hline Always observing mice around home & $21(47.73 \%)$ & $37(24.34 \%)$ & $3.1(1.5-6.6)$ & $3.7(1.4-9.9)$ & 0.008 \\
\hline Sex (males) & $27(61.4 \%)$ & $65(42.8 \%)$ & $2.0(1.0-4.1)$ & $1.4(0.5-3.8)$ & 0.518 \\
\hline
\end{tabular}

The model adjusted for: sex, field work group, use of personal protective equipment in the field, urinating in the forest/near bushes/field, using the same work clothes the next day, changing clothes when at home, always observing of mice around home, raising cattle, seeing chickens that you raise have mites, passing riverside, sitting/laying directly on household floor, household with poor sanitation/conditions, household surroundings with risk, workplace environment with risk

${ }^{a} \mathrm{mOR}$, matching odds ratio, using univariable conditional logistic regression; ${ }^{\mathrm{b}} \mathrm{aOR}$, adjusted odds ratio, using multivariable conditional logistic regression

people at risk need a full protective equipment to prevent infected mites climbing up any body parts while working/sitting in the field.

\section{Households with poor sanitation/conditions}

Households with poor sanitation/conditions ( $\mathrm{HH}$ with drainage on ground-not including grassy edges of water bodies, or $\mathrm{HH}$ with a muddy/sandy yard or $\mathrm{HH}$ with a muddy floor) represented an important risk factor in this study. Water drainage or seepage in drier areas was defined as a crucial micro-ecology favoring the presence of chiggers and increased risk of acquiring scrub typhus [7, 41, 42]. Common chigger habitats are grassy edges, soil dampness, and a well nearby the household [41, 42, 49], but water drainage on the household ground/premises was not considered $[20,50,51]$. A sandy/muddy yard or a muddy house floor take up dampness through water drainage after rainfall, which fosters survival of chiggers. Chigger abundance could be maintained by sprinkling the ground with water after rains in Malaysia [52].

\section{Workplace environment with risk}

Workplace environment with risk (i.e. close to forest/hilly field/water bodies within $100 \mathrm{~m}$ or bushes within $10 \mathrm{~m}$ ) was associated with scrub typhus acquisition $(\mathrm{aOR}=3.0$, 95\% CI: 1.2-7.6). To note is that more importantly than occupation. Working in forests/hilly fields were common risk factors $[24,45,53]$. However, in previous studies, daily activities were often indicated as individual "long-term" activities [53], rather than "workplace environment". In our study, we expressed "workplace environment with risk" based on the wide diversity of work activities in this surrounding and by duration (about $1 \mathrm{~h} /$ day), rather than by one long-lasting single work. In Khanh Hoa, not being named by any specified job title, working close to forests/hilly fields included varied typical occupations (self-business/hired) such as herding cows, mowing grass for livestock, picking up firewood, planting vegetation into forest streams, wood truck driver, loading fruits/sugarcane. Therefore, "workplace environment with risk" was a more relevant and broader definition than a single type of occupation. This approach may be more useful for medical staffs to locate risk areas and initiate preventive measures, than focusing only on specific jobs/occupations.

Working near water bodies (lakes/ponds/streams/ channels/wells/irrigation systems surrounded by vegetation or seepages within $100 \mathrm{~m}$ ) was a major risk factor for scrub typhus [41, 42, 49]. We identified typical local seepages such as sand fields, beaches, coastlines as a special working habitat of people planting garlic on sand, fishermen, throwing fishing nets, and catching seafood. This is geographically relevant for Khanh Hoa [27]. Sandy fields and beaches represent preferred environments for mites and chiggers [7]. Orientia spp. vectors and hosts have been described along sandy beaches in Malaysia [54]. Leptotrombidium arenicola spp. has been detected in vegetation alongside beaches in Southeast Asia [39, 55].

\section{Farmer or agriculture work is a "vague" risk factor definition in Vietnam}

Farmers represent a high risk population for scrub typhus due to their long time exposure in fields $[45,53$, 56]. However, we could not find this, which could be explained by following reasons: (i) different rates of preexisting immunity through repeated exposure in highly endemic areas; (ii) a patchy distribution of chiggers in the environment (chigger islands), which are dependent on rodent density in this region, (iii) a different perception/ definition of occupation as "farmer", and (iv) multiple people perform multiple work-related activities, representing a "mixed" risk profile.

Association between farmer/occupation and scrub typhus varied across endemic areas, depending on both activity and environment in which cases were exposed to. A hospital-based study reported that agricultural labour 
was associated with an increased risk for scrub typhus in Jiangsu province, China $(\mathrm{aOR}=2.9,95 \%$ CI: $1.5-5.8)$ [57]. However, in Uttarakhand, India, housewives (52\%) and students (28\%) were the two major occupational subgroups among scrub typhus patients (while farmers were $11.11 \%$ ), thus likely representing previously non-exposed people with no pre-existing immunity, that participated in local harvests in fields, rather than their usual urbanbased occupations [58]. Among community-based studies, an association between farming and occurrence of scrub typhus was reported for India $(\mathrm{aOR}=2.0,95 \% C I$ : 1.1-3.5 [24], $\mathrm{mOR}=10.0$; 95\% CI: $2.7-63.0$ [45]) and for the Lao PDR ( $\mathrm{mOR}=2.1,95 \%$ CI: 1.0-4.2) [59]. However, in a scrub typhus outbreak in Guangzhou, China (2012), no patients engaged in agricultural activities. The outbreak was finally assigned due to outdoor exercises in a local park [60].

This study revealed that the term "farmer" or "agricultural work" is often perceived as a "vague" definition in Vietnam. This was more pronounced in rural study areas, and often people defined themselves as farmers when their family owned a field, even if they hired others for farming or did no agricultural work for a long time. Indepth clarification of our study revealed that a proportion of $25.5 \%$ agricultural labours did no farming within the preceding 3 weeks prior to onset. In contrast, 27.5\% persons indicating that they were officers/factory workers/students/small businessmen, involved agricultural/ forest activities during that period. Further, a personhired for agricultural work (cultivating, harvesting for 2-10 days), described themselves as "work-for-hire", not as "farmer". Therefore, using occupation/farmer to examine risk of scrub typhus in Vietnam could introduce bias into associations.

People with multiple occupations/work activities were common in our study setting. A participant could have multiple jobs, i.e. a nurse after night work-shift had a dayoff and mowed grass for cows; or a hotel waiter worked as gardener for the hotel and as tour guide. Over 50\% participants had at least 3 varied activities in the preceding 3 weeks exposure period, often including farming, cultivating crops (hired), cow herding (hired), fishing, planting acacia trees on hilly areas. A high mobility was noted among these patients. In the 3 weeks before disease onset, next to cultivating, a person could work as wood/ sugarcane truck driver, loading fruits, herding cows, mowing grass, laying bricks (hired) or coastal fishing. Farming is a seasonal occupation, whereby most do not work full-time in the fields, even during the 3-4 months farming season. Therefore, in "non-farming time", these people are occupied with other exposures/jobs/activities.

The collated data suggests that farmer/occupation is likely not a clear indicator of scrub typhus infection.
Workplace environment is more practical than farmer/ occupation to examine that association. Workplace environment, covering and representative for all activities in such risk area, is likely a better approach for a risk assessment of acquiring scrub typhus.

\section{Always observing mice around home}

Always observing mice around home" was one of the risk factors for scrub typhus in this study, similar to other studies $[45,60](\mathrm{aOR}=3.7,95 \% \mathrm{CI}: 1.4-9.9)$. This finding is supported by available evidence on the presence of Orientia spp. infected Leptotrombidium deliense spp. and Ascoschoengastia indica spp. among house rodents in Khanh Hoa [53].

\section{Difference in risk factors between hospital and community controls}

In independent analyses of case-community controls, we found that sitting/laying directly on $\mathrm{HH}$ floor was a risk factor of scrub typhus only among persons in the same commune, whereas "always observing mice around home" was not (aOR=2.7, 95\% CI: 0.7-10.3, Additional file 2: Table S2). These findings could be explained due to the fact that confirmed cases and their community controls lived in the same area (within $500 \mathrm{~m}$ ) and shared similar ecological characteristics such as mice/rodent density [7]. Therefore, we did not observe a difference in presence of mice around their houses. However, sitting/laying directly on $\mathrm{HH}$ floor was the most important risk factor among persons in the same communes. It was likely the strong evidence on association between direct infected mite exposure and scrub typhus, confirming transmission of O. tsutsugamushi spp. among mites and between mites-house mice in these hyper endemic communes. Independent analyses of case-hospital controls (i.e. living in different communes) showed that always observing mice around home was more clearly associated with $O$. tsutsugamushi infection, with aOR $=5.4,95 \% \mathrm{CI}$ : 1.7-17.1 (Additional file 3: Table S3). This finding was also supported for transmission of $O$. tsutsugamushi spp. among mites and house mice in cases' communes.

\section{Study highlights}

Reported common risk factors for scrub typhus are bushes around house/working place [45, 51, 53, 61-64], always observing mice around home [45, 60], and working near forest/hilly fields [24, 45, 53]. In this study, we highlighted additional factors for Khanh Hoa, including (i) sitting/laying directly on $\mathrm{HH}$ floor; (ii) use of full PPE set (socks, boots, long/extra shirt, long/extra trousers, gloves) in the field, (iii) changing of clothes when at home; (iv) $\mathrm{HH}$ with sandy or muddy grounds/a muddy floor, or $\mathrm{HH}$ with drainage on ground; and (v) workplace 
near sandy fields. This study assessed ecological and behavioural risk factors, based on the full landscape framework [35] and an ecological epidemiology approach in a comprehensive in-depth questionnaire, which allowed the identification of proximal and more distal ecological factors.

\section{Consequences for control and elimination}

Facing challenges to detect scrub typhus cases in Vietnam despite limitations in diagnostics, the risk factors found in this study, combined with better known clinical symptoms and epidemiology, should be presented in training courses at hospitals and for doctors trained on the emerging scrub typhus. Epidemiological risk factors and illness case-detection have improved with this study.

The factors identified in this study are useful to support establishment of preventive measures, inform regional surveillance, and promote much-needed effective public health responses against scrub typhus after many decades of neglect in Vietnam. Currently, there are no disease prevention and control strategy for scrub typhus or rodents in Khanh Hoa and Vietnam-however, we found this an important risk factor. To note is that rodent control in settlements can also prevent other diseases such as plague or leptospirosis [65]. Facing current limitations in diagnostic capacity for scrub typhus in Central Vietnam, especially at primary health care levels, these findings will support local education and allow local people in hyper-endemic areas to increase their risk factor knowledge and protect themselves from scrub typhus.

\section{Limitations of the study}

This was an exploratory study given that no known set of risk factors for Vietnam could be confirmed. A retrospective study design is prone to recall bias. However, in this study, defining and enrolling participants to the study was no longer than 1 month since the date of the case confirmation and asking for a 3 week exposure period to minimise recall bias. The initial sample size was adjusted due to the COVID-19 pandemic, which reduces statistical power to detect associations between use of PPE in the field and scrub typhus. However, the study was obviously sufficiently powered to detect several important risk factors. Further, our results might only apply for provinces in same ecological and endemic zone like Khanh Hoa, which are the 11 central provinces in Vietnam.

\section{Conclusions}

Ecological and household hygiene related factors such as $\mathrm{HH}$ with poor sanitation/conditions, always observing mice around home, and workplace environment with risk were associated with Orientia spp. infection, rather than individual-level exposure activities. Use of PPE in the field and changing clothes when at home were potential protective factors.

\section{Abbreviations}

PCR: Polymerase chain reaction; IFA: Indirect immunofluorescence assay; EDTA Ethylenediaminetetraacetic acid; ELISA: Enzyme-linked immunosorbent assay; COVID-19: Coronavirus disease 2019; IgM: Immunoglobulin M; PPE: Personal protective equipment; ID: Identification number; HH: Household; AIC: Akaike information criterion.; IPN: Nha Trang Pasteur Institute.

\section{Supplementary Information}

The online version contains supplementary material available at https://doi. org/10.1186/s40249-021-00893-6.

Additional file 1: Table S1. Inclusion and exclusion criteria of scrub typhus suspected, confirmed cases and hospital controls, community controls.

Additional file 2: Table S2. Risk factors of scrub typhus resulting from case-hospital control analyses.

Additional file 3: Table S3. Risk factors of scrub typhus resulting from case-community control analyses.

Additional file 4: Figure S1. Visualisation of 5 main items regarding ST risk factors to be assessed in Khanh Hoa.

\section{Acknowledgements}

We would like to express our deep gratitude to the directors, senior hospital managers, staffs working at the planing and general departments, medical doctors, nurses and patients at the 11 study hospital: Khanh Hoa Provincial Hospital; Ninh Hoa Hospital, Khanh Hoa Hospital for Tropical Diseases; the 87 Army Hospitals and 7 district hospitals for their generous support and interest in this project. Special thanks to Phung Tan Le, the Deputy Director, and Quan Hong Do of the Khanh Hoa Department of Health, for their approval of the study implemetation in Khanh Hoa province. We would like to give many thanks to Mlacha Yeromin for his help on the case and control distribution maps. Further, we are grateful to Mai Quang Vien and Hung Do Manh for their help and advice in setting up this study. Finally, we would like to give special thanks to all heads and staffs of the commune health centers, and the village health workers for their great support in verification of participants and assisting in the field study investigations.

\section{Authors' contributions}

Conceptualization and study design: ES, HTDT, JZ; Data collection: HTDT, HMD, HHH, TTH, HNL; Data curation: HTDT, JH; Data analysis: HTDT, JH, LTHV; Laboratory work: MHK; Writing-review \& editing: HTDT, JH, LTHV, JZ, DHP, ES. All authors read and approved the final manuscript.

\section{Funding}

Research reported in this publication is a part of Hanh Tran's PhD project "Scrub typhus in Khanh Hoa, Viet Nam: an eco-epidemiological approach". This ongoing PhD work is financially partly covered by the Swiss Government Excellence Scholarship Award from 9/2017 to 12/2020. The remaining salary is covered by Esther Schelling and Daniel H. Paris. Esther Schelling funded the data collection and field trips. Daniel H. Paris funded the laboratory assays and technical laboratory training course. This data collection in Vietnam was also supported by a Wolfermann-Nägeli-Stiftung Award for Project TsutsugamushiFieber (scrub typhus) in Khanh Hoa, Viet Nam (Hanh Thi Duc Tran PhD Candidate). The content is solely the responsibility of the authors.

\section{Availability of data and materials}

The datasets used and/or analysed during the current study are available from the corresponding author on reasonable request. 


\section{Declarations}

\section{Ethical approval and consent to participate}

Ethical approval was granted by the Scientific and Ethical Committee in Biomedical Research, Hanoi University of Public Health (No.382/2018/YTCC-HD3 and No.329/2019/YTCC-HD3) and by the Ethics Committee of Northwestern and Central Switzerland (Ethikkommission Nordwest- und Zentralschweiz, EKNZ) (BASEC-Nr-2018-00974). The study implementation was approved by the Provincial Health Department of Khanh Hoa at the document No 2192/ SYT-NVY signed 16 August 2018. All participants were asked for their consent before enrolling in the study and had the right to withdraw from the study at any time without any threat or disadvantage. All patients provided written informed consent prior to study enrollment and sample collection.

\section{Consent for publication}

Not applicable.

\section{Competing interests}

The authors declare that there are no competing interests.

\section{Author details}

'Department of Epidemiology and Public Health, Swiss Tropical and Public Health Institute, Basel, Switzerland. ${ }^{2}$ Department of Epidemiology, Hanoi University of Public Health, Hanoi, Vietnam. ${ }^{3}$ University of Basel, Basel, Switzerland. ${ }^{4}$ Department for Infectious Disease Control and Prevention, Nha Trang Pasteur Institute, Nha Trang, Khanh Hoa, Vietnam. ${ }^{5}$ Institute of Gastroenterology and Hepatology, Hanoi, Vietnam. ${ }^{6}$ Department of Microbiology and Immunology, Nha Trang Pasteur Institute, Nha Trang, Khanh Hoa, Vietnam. ${ }^{7}$ Faculty of Medicine, University of Basel, Basel, Switzerland. ${ }^{8}$ Department of Medicine, Swiss Tropical and Public Health Institute, Basel, Switzerland. ${ }^{9}$ Vétérinaires Sans Frontières Suisse, Bern, Switzerland.

Received: 28 April 2021 Accepted: 4 August 2021

Published online: 19 August 2021

\section{References}

1. LVY, Guo XG, Jin DC. Research progress on leptotrombidium deliense Korean J Parasitol. 2018;56:313-24.

2. Peng PY, Guo XG, Ren TG, Dong WG, Song WY. An updated distribution and hosts: trombiculid mites (Acari: Trombidiformes) associated with small mammals in Yunnan Province, southwest China. Parasitol Res. 2016:115:1923-38.

3. Traub R, Wisseman CL Jr. Ecological considerations in scrub typhus. 2. Vector species. Bull World Health Organ. 1968;39:219-30.

4. Paris DH, Kelly DJ, Fuerst PA, Day NPJ, Richards AL. A brief history of the major rickettsioses in the Asia-Australia-Pacific Region: a capstone review for the special issue of TMID. Trop Med Infect Dis. 2020;5:165.

5. JR A. The ecology of scrub typhus. In: May JM, editor. Studies in disease ecology. New York: Hafner Publishing Company, Inc. 1961.

6. Fletcher W, Lesslar JE, Lewthwaite R. The ætiology of the tsutsugamush disease and tropical typhus in the Federated Malay States. Trans R Soc Trop Med Hyg. 1928;22:161-74.

7. Elliott I, Pearson I, Dahal P, Thomas NV, Roberts T, Newton PN. Scrub typhus ecology: a systematic review of Orientia in vectors and hosts. Parasit Vectors. 2019:12:513.

8. Koh GC, Maude RJ, Paris DH, Newton PN, Blacksell SD. Diagnosis of scrub typhus. Am J Trop Med Hyg. 2010;82:368-70.

9. Cracco C, Delafosse C, Baril L, Lefort Y, Morelot C, Derenne JP, et al. Multiple organ failure complicating probable scrub typhus. Clin Infect Dis. 2000:31:191-2.

10. Wangrangsimakul T, Greer RC, Chanta C, Nedsuwan S, Blacksell SD, Day NPJ, et al. Clinical characteristics and outcome of children hospitalized with scrub typhus in an area of endemicity. J Pediatric Infect Dis Soc. 2020:9:202-9.

11. Paris DH, Dumler JS. State of the art of diagnosis of rickettsial diseases: the use of blood specimens for diagnosis of scrub typhus, spotted fever group rickettsiosis, and murine typhus. Curr Opin Infect Dis. 2016:29:433-9.
12. Luce-Fedrow A, Mullins K, Kostik AP, St John HK, Jiang J, Richards AL. Strategies for detecting rickettsiae and diagnosing rickettsial diseases. Future Microbiol. 2015:10:537-64.

13. Kingston HW, Blacksell SD, Tanganuchitcharnchai A, Laongnualpanich A, Basnyat B, Day NP, et al. Comparative accuracy of the InBios Scrub Typhus Detect IgM Rapid Test for the detection of IgM antibodies by using conventional serology. Clin Vaccine Immunol. 2015:22:1130-2.

14. Paris DH, Shelite TR, Day NP, Walker DH. Unresolved problems related to scrub typhus: a seriously neglected life-threatening disease. Am J Trop Med Hyg. 2013;89:301-7.

15. Bonell A, Lubell Y, Newton PN, Crump JA, Paris DH. Estimating the burden of scrub typhus: a systematic review. PLoS Negl Trop Dis. 2017;11:e0005838.

16. Xu G, Walker DH, Jupiter D, Melby PC, Arcari CM. A review of the global epidemiology of scrub typhus. Plos Negl Trop Dis. 2017;11:e0006062.

17. Hamaguchi S, Cuong NC, Tra DT, Doan YH, Shimizu K, Tuan NQ, et al. Clinical and Epidemiological characteristics of scrub typhus and murine typhus among hospitalized patients with acute undifferentiated fever in Northern Vietnam. Am J Trop Med Hyg. 2015;92:972-8.

18. Chau NV, Trombiculidae mite and association with scrub typhus in Quang Ninh. National Institute of Malariology, Parasitology and Entomology: Hanoi. 2003.

19. Nadjm B, Thuy PT, Trang VD, le Ha D, Kinh NV, Wertheim HF. Scrub typhus in the northern provinces of Vietnam: an observational study of admissions to a national referral hospital. Trans R Soc Trop Med Hyg. 2014;108:739-40.

20. Do H, Nguyen N, Dao A, Vo D, Le T, and Vien M, Epidemiological characteristics of scrub typhus in Khanh Hoa, Nha Trang Pasteur Institute. 2014.

21. Katoh S, Cuong NC, Hamaguchi S, Thuy PT, Cuong DD, Anh LK, et al. Challenges in diagnosing scrub typhus among hospitalized patients with undifferentiated fever at a national tertiary hospital in northern Vietnam. PLoS Negl Trop Dis. 2019;13:e0007928.

22. Ma CJ, Oh GJ, Kang GU, Lee JM, Lee DU, Nam HS, et al. Differences in agricultural activities related to incidence of scrub typhus between Korea and Japan. Epidemiol Health. 2017;39:e2017051.

23. Singh SI, Devi KP, Tilotama R, Ningombam S, Gopalkrishna Y, Singh TB, et al. An outbreak of scrub typhus in Bishnupur district of Manipur, India, 2007. Trop Doct. 2010:40:169-70.

24. Varghese G, Raj D, Francis M, Sarkar R, Trowbridge P, Muliyil J. Epidemiology \& risk factors of scrub typhus in south India. Indian J Med Res. 2016;144:76-81.

25. Kelly DJ, Richards AL, Temenak J, Strickman D, Dasch GA. The past and present threat of rickettsial diseases to military medicine and international public health. Clin Infect Dis. 2002;34:S145-69.

26. Pasteur Institute of Nha Trang, Scrub typhus Clinical Characteristics in Khanh Hoa, VietNam. 2017

27. The People's Committee of Khanh Hoa Province. Khanh Hoa Introduction 2015. https://www.khanhhoa.gov.vn/english-portal. Accessed 21 Jan 2021.

28. National Hydro-Meteorological Service MoNRaE, Monthly climate data, 1979-2014. 2014

29. Deaton JG. Febrile illnesses in the tropics (Vietnam). Mil Med. 1969:134:1403-8

30. Pasteur Institute of Nha Trang. SOP — the in-house semi-nested polymerase chain reaction (semi-nested PCR) for Orientia tsutsughamushi spp. antigen 2014.

31. Vietnam Ministry of Health. National guideline on diagnosis and treatment some infectious diseases. Hanoi: Medical Publisher; 2016.

32. Paris DH, Richards AL, Day NPJ, et al. Chapter 112 - Orientia. In: Sussman $\mathrm{M}$, et al., editors. Molecular medical microbiology (Second Edition). Boston.: Academic Press; 2015. p. 2057-96

33. Koraluru M, Bairy I, Varma M, Vidyasagar S. Diagnostic validation of selected serological tests for detecting scrub typhus. Microbiol Immunol. 2015;59:371-4.

34. Blacksell SD, Kingston HWF, Tanganuchitcharnchai A, Phanichkrivalkosil M, Hossain M, Hossain A, et al. Diagnostic accuracy of the InBios Scrub Typhus Detect ${ }^{\text {TM }}$ ELISA for the detection of igm antibodies in Chittagong, Bangladesh. Trop Med Infect Dis. 2018;3:95.

35. Lambin EF, Tran A, Vanwambeke SO, Linard C, Soti V. Pathogenic landscapes: interactions between land, people, disease vectors, and their animal hosts. Int J Health Geogr. 2010;9:54. 
36. Ngo Q, Trinh L, Nguyen D, Nguyen T, Ngo N, Vien M. Survey on scrub typhus due to Rickettsia tsutsugamushi in Khanh Hoa province. Vietnam Vietnam J Prev Med. 2017:27:110.

37. The Open Data Kit community. Collect data anywhere. 2020. https:// getodk.org/. Accessed 23 Sept 2020

38. Audy JR. Scrub typhus as a study in ecology. Nature. 1947;159:295.

39. Audy J. A Summary topographical account of scrub typhus 1908-1946. Studies in the distribution and topography of scrub typhus, Number 1. 1949.

40. Suzuki T. Studies on the bionomics and chemical control of tsutsugamushi (scrubtyphus mites). II. Trombicula scutellaris Nagayo et al. in southern Kanto of Japan. Jpn J Exp Med. 1954;24:181-97.

41. Audy JR. Practical notes on scrub typhus in the field. J Royal Army Med Corps. 1949;93:273.

42. Audy JR, Harrison JL. A review of investigations on mite typhus in Burma and Malaya, 1945-1950. Trans R Soc Trop Med Hyg. 1951;44:371-404.

43. Kuo CL, Duan Y, Grady J. Unconditional or conditional logistic regression model for age-matched case-control data? Front Public Health. 2018;6:57.

44. Vien M, Ngo Q, Nguyen H, Trinh L, Nguyen D, Nguyen T. Evaluation for test results of scub typhus caused by Rickettsia tsutsugamushi in Khanh Hoa province, during 2013-2014. Vietnam J Prev Med. 2015; XXV:110.

45. Puran S. Risk factors for scrub typhus and typhoid in the Kurseong subdivision of Darjeeling district, West Bengal, India, 2005-2006 (Master of Applied Epidemiology). (Chennai, India): National Institute of Epidemiology (Indian Council of Medical Research); 2006.

46. Wei Y, Luo L, Jing Q, Li X, Huang Y, Xiao X, et al. A city park as a potential epidemic site of scrub typhus: a case-control study of an outbreak in Guangzhou. China Parasit Vectors. 2014;7:513.

47. Kweon SS, Choi JS, Lim HS, Kim JR, Kim KY, Ryu SY, et al. A communitybased case-control study of behavioral factors associated with scrub typhus during the autumn epidemic season in South Korea. Am J Trop Med Hyg. 2009;80:442-6.

48. Sharma PK, Ramakrishnan R, Hutin YJ, Barui AK, Manickam P, Kakkar M et al. Scrub typhus in Darjeeling, India: opportunities for simple, practical prevention measures. Trans R Soc Trop Med Hyg. 2009;103:1153-8.

49. Audy JR BJ, Browning HC, Bullock AA, Cockings KL, Ford W, et al. Scrub typhus investigations in South East Asia. A report on investigations on scrub typhus by G.H.Q. (India) Field Typhus Research Team, and the Medical Research Council Field Typhus Team, based on the Scrub Typhus Research Laboratory, South East Asia Command, Imphal. Part 1. General account. Part 2. Illustrations. Part 3. Appendices. London: War Office. 1947.

50. Kamble S, Mane A, Sane S, Sonavale S, Vidhate P, Singh MK, et al. Seroprevalence \& seroincidence of Orientia tsutsugamushi infection in Gorakhpur, Uttar Pradesh, India: a community-based serosurvey during lean (April-May) \& epidemic (October-November) periods for acute encephalitis syndrome. Indian J Med Res. 2020;151:350-60.

51. Rose W, Kang G, Verghese VP, Candassamy S, Samuel P, Prakash JJA, et al. Risk factors for acquisition of scrub typhus in children admitted to a tertiary centre and its surrounding districts in South India: a case control study. BMC Infect Dis. 2019;19:665.
52. Gentry JW, Phang OW, Manikumaran C. The effects of rainfall on trombiculid (Acarina:trombiculidae) larval populations in peninsular Malaysia. Southeast Asian J Trop Med Public Health. 1977:8:217-20.

53. Lyu $Y$, Tian $L$, Zhang L, Dou $X$, Wang $X$, Li W, et al. A case-control study of risk factors associated with scrub typhus infection in Beijing, China. PLoS One. 2013;8:e63668

54. Traub R. Two new species of chiggers of the genus Leptotrombidium (Acarina, Trombiculidae). Malaysian parasites. 1960; XLV Stud Inst Med Res Malaya. pPp. 198-204.

55. Dohany AL, Lim BL, Huxsoll DL. Vectors of scrub typhus and their hosts on a mature oil palm estate. Southeast Asian J Trop Med Public Health. 1979;10:510-3.

56. Zhang WY, Wang LY, Ding F, Hu WB, Magalhaes RJS, Sun HL, et al. Scrub typhus in mainland China, 2006-2012: the need for targeted public health interventions. PLoS Negl Trop Dis. 2013;7:e2493.

57. Hu JL, Tan ZM, Ren DF, Zhang X, He YL, Bao CJ, et al. Clinical characteristics and risk factors of an outbreak with scrub typhus in previously unrecog nized areas, Jiangsu Province, China 2013. PLoS One. 2015;10:e0125999.

58. Pathania M, Amisha, Malik P, Rathaur VK. Scrub typhus: Overview of demographic variables, clinical profile, and diagnostic issues in the subHimalayan region of India and its comparison to other Indian and Asian studies. J Family Med Prim Care. 2019;8:1189-1195.

59. Vallee J, Thaojaikong T, Moore CE, Phetsouvanh R, Richards AL, Souris M, et al. Contrasting spatial distribution and risk factors for past infection with scrub typhus and murine typhus in Vientiane City, Lao PDR. PLoS Negl Trop Dis. 2010;4:e909.

60. Wei Y, Luo L, Jing Q, Li X, Huang Y, Xiao X, et al. A city park as a potential epidemic site of scrub typhus: a case-control study of an outbreak in Guangzhou. China. Parasit Vectors. 2014;7:513. https://doi.org/10.1186/ s13071-014-0513-7.

61. Gautam R, Parajuli K, Sherchand JB. Epidemiology, risk factors and seasonal variation of scrub typhus fever in Central Nepal. Trop Med Infect Dis. 2019:4:27.

62. Thangaraj JWV, Vasanthapuram R, Machado L, Arunkumar G, Sodha SV, Zaman $\mathrm{K}$, et al. Risk factors for acquiring scrub typhus among children in Deoria and Gorakhpur Districts, Uttar Pradesh, India, 2017. Emerg Infect Dis. 2018;24:2364-7.

63. Trowbridge P, Divya P, Premkumar PS, Varghese GM. Prevalence and risk factors for scrub typhus in South India. PLoS Negl Trop Dis. 2017:22:576-82.

64. Ambilkar A, Jogdande A, Thakre S, Nimgade SD, Chauragade VM, Patle BR. Determinants of scrub typhus: a case control study in Tribal Region of Eastern Maharashtra. J Med Res. 2019;5:94-7.

65. Morand S, Blasdell K, Bordes F, Buchy P, Carcy B, Chaisiri K, et al. Changing landscapes of Southeast Asia and rodent-borne diseases: decreased diversity but increased transmission risks. Ecol Appl. 2019:29:e01886.

Ready to submit your research? Choose BMC and benefit from

- fast, convenient online submission

- thorough peer review by experienced researchers in your field

- rapid publication on acceptance

- support for research data, including large and complex data types

- gold Open Access which fosters wider collaboration and increased citations

- maximum visibility for your research: over 100M website views per year

At $\mathrm{BMC}$, research is always in progress.

Learn more biomedcentral.com/submissions 